\title{
An investigation of scaffolded reading on EFL hypertext comprehension
}

\author{
Hui-Fang Shang \\ I-Shou University, Taiwan
}

\begin{abstract}
With the rapid growth of computer technology, some printed texts are designed as hypertexts to help EFL (English as a foreign language) learners search for and process multiple resources in a timely manner for autonomous learning. The purpose of this study was to design a hypertext system and examine if a 14-week teacher-guided print-based and hypertext reading intervention might benefit non-traditional EFL students' reading comprehension. Non-traditional EFL students are older students with greater work experience. The primary investigation finding revealed no significant difference in comprehension between the teacher-guided print-based and hypertext intervention conditions, though a significant mean improvement was found after hypertext learning. EFL learners' attitudes also supported that both teacher-guided print-based and hypertext interventions merit reading comprehension performance. In addition, there appears to be a significantly strong and positive relationship between the perceived usefulness of hypertext reading and attempt of future hypertext use, suggesting that the majority of non-traditional EFL learners made a positive willingness and prediction to use the hypertext system in their future reading, but that the degree of usefulness of hypertext reading was not reliably predicted by their hypertext comprehension scores. Based on the investigation results, limitations and future research are discussed and presented.
\end{abstract}

\section{Introduction}

Recent research on the subject of reading has shown that reading exists as a complex cognitive activity indispensable for adequate functioning and for obtaining information in contemporary society (Alfassi, 2004; Zhang, 1993). To enter any literate society, students must know how to learn from reading in order to succeed. However, students in Taiwan often select ineffective and inefficient strategies with little strategic intent (Ko, 2002). Many Taiwanese English as a foreign language (EFL) students assume that the intended author's meaning lies within the printed words, leaving the reading process no more than obtaining meaning from the words on the page. EFL students in Taiwan approach reading passively, relying heavily on the use of a bilingual dictionary, thereby spending countless hours labouring over direct sentence-by-sentence translations. Despite all the efforts made, students' reading comprehension remains poor (Shang, 2010).

For too many EFL students, reading failure is a persistent problem; not all readers have the essential knowledge to master reading strategies and experiences to relate to the text (Chen, Teng, Lee, \& Kinshuk, 2011). Effective and appropriate scaffolding is, therefore, necessary to meet the needs of students to cope with the reading difficulties mentioned above (Ritchey, Silverman, Montanaro, \& Schatschneider, 2012). Scaffolding is a conception of providing students with necessary learning support to resolve what they cannot accomplish alone to achieve the ultimate goal of reading (Wood, Bruner, \& Ross, 1976), and it has been a flexible and effective strategy in assisting EFL students doing high-order cognitive reading activities by using pre-, during-, and post-reading strategies (Chen et al., 2011). A considerable number of studies have suggested the advantages of applying scaffolding strategies in reading pedagogy to enhance the ability of inquiry ( $\mathrm{Li} \& \mathrm{Lim}, 2008$ ), problem solving (Kim \& Hannafin, 2011), and reading comprehension performance (Cooke, 2002; Fournier \& Graves, 2002; Graves \& Liang, 2003).

With the rapid growth of computer technology, computer-based instruction (CBI) has been a popular scaffolded teaching tool used worldwide to motivate students to learn autonomously (Gunduz, 2005; Higgins, 1995). Thus, some printed texts are designed as hypertexts to help learners search for and process multiple resources in a timely manner (Iiyoshi, Hannafin, \& Wang, 2005; Wang, Kinzie, \& McGuire, 2010). Although comprehending a hypertext as an "analog to traditional reading environments" (Lawless \& Kulikowich, 1996, p. 385) requires the same cognitive processes involved in reading a 
printed text, hypertexts differ dramatically from traditional texts in that they provide readers with the opportunity to interact with the text (Lawless, Brown, Mills, \& Mayall, 2003). Hypertexts in particular provide new text formats, new purposes for reading, and new ways to interact with information that can help to extract meaning from traditional paper-based texts to attain higher comprehension scores and degree of satisfaction (Chen et al., 2011; Huang, Chern, \& Lin, 2009; MacArthur \& Haynes, 1995; Ray, 2004; Ray \& Belden, 2007).

Since hypertext is likely to become more dominant in the future, few attempts have been made to examine non-traditional EFL students' attitudes towards their e-learning experience and its impact on their reading outcomes. Non-traditional students in Taiwan are older and have more social and working experiences than traditional students. They also have different learning processes and needs; it is important to use various instructional approaches to arouse their motivation for autonomous learning (Liang \& Lai, 2003). Nevertheless, their particular needs and reading outcomes have often been neglected (Shang, 2005). It is assumed that non-traditional EFL students should have positive user attitudes towards the feature of the hypertext learning context since most of them have jobs during the daytime; it is more convenient for them to read the hypertexts online. Thus, they may show strong preferences for the online learning context due to the reduced constraints on physical location or time of day. Little research, however, has been done by reading researchers and educators to assess whether or not the act of non-traditional EFL students' reading differs across print and hypertext environments, as well as the well-structured hypertext's potential impact on reading comprehension. Furthermore, non-traditional EFL students' psychological engagement has a significant impact on software use and ongoing autonomous learning, and therefore should be investigated thoroughly. To explore how variables such as traditional print, hypertext, and e-learning experience influence reading comprehension from a hypertext environment in a Taiwanese learning context, an e-learning system was designed and developed to compare the effect of conventional face-to-face teacher-guided print-based and online hypertext reading interventions. It is hypothesised that positive effects of using the e-learning hypertext system to enhance non-traditional EFL students' learning interest and reading comprehension can be observed.

\section{Literature review}

\section{EFL reading comprehension}

Reading is an interactive process combining top-down and bottom-up processing (Barnett, 1989). The major purpose of reading a document is comprehension (Protopsaltis \& Bouki, 2005). Reading comprehension, as defined within schema theory, is "the process of the interpretation of new information, and the assimilation and accommodation of this information into memory structures or schemata" (Lawless et al., 2003, p. 913). Wixson and Peters (1984) described reading comprehension as "the process of constructing meaning through the dynamic interaction among the reader's existing knowledge, the information suggested by the written language, and the context of the reading situation” (p. 5). To enhance reading comprehension, several factors need to be considered, such as vocabulary, prior/background knowledge, textual clues, intrinsic motivation or interest, as well as strategic behaviours for monitoring (Lawless et al., 2003; Ritchey et al., 2012).

As mentioned earlier, Taiwanese EFL students' reading comprehension remains poor (Shang, 2010), especially for those learners with a low English proficiency level. Cheng (2000) found that when reading easy English and Chinese texts, Taiwanese students' use of reading strategies is similar, but when they are presented with difficult Chinese and English texts, their use of strategies in reading the Chinese text is more meaning-focused or global. In contrast, when they read the English text, they employ more low-level or local processing strategies. Since it is not easy to be a constructive and effective English language reader (Dole, Duffy, Roehler, \& Pearson, 1991; Shuell, 1986), the reading process should be scaffolded by an appropriate intervention with multiple representations in order to enhance EFL learners' reading comprehension (Chen et al., 2011; Paris \& Oka, 1989). 


\section{Scaffolded reading}

As discussed earlier, comprehension is the ultimate goal of reading instruction (Protopsaltis \& Bouki, 2005). Effective and appropriate intervention or scaffolding is, therefore, necessary to meet the needs of EFL readers (Ritchey et al., 2012). The term scaffolding was first used by Wood et al. (1976), who used it to characterise mothers' verbal interaction when reading to their children (Fitzgerald \& Graves, 2005). Scaffolding later in the educational sense refers to the process that enables a novice to solve a problem or achieve a goal which would not be possible to achieve without some external help (Chen et al., 2011). Numerous studies have shown that teachers' scaffolded instruction has been recognised as an important way to help EFL learners use paper-reading strategies effectively so as to read more productively and gain a fuller understanding of the text (Chang, 1998; Cheng, 1998; Fitzgerald \& Graves, 2005; Sheorey \& Mokhtari, 2001). Wharton-McDonald, Pressley, and Jampston's (1998) study also illustrated that teachers whose students demonstrate higher-level achievement in reading and writing extensively use scaffolding in instruction among other successful practices.

To help English language learners master both reading and content effectively, Graves and Graves (2003) proposed an instructional framework for reading - scaffolded reading experience (SRE). An SRE is designed to broaden English language learners' repertoires of reading strategies and skills; it consists of a set of pre-, during-, and post-reading activities (Fitzgerald \& Graves, 2005). Pre-reading activities are developed to prepare or motivate EFL students to read the selected material, relate the content to students' prior knowledge, and activate their background knowledge. During-reading activities are what EFL students or teachers do to assist or guide students' understanding as they are reading. Post-reading activities are designed to synthesise the content and evaluate EFL students' understanding of the text. Studies have shown that students score significantly higher when receiving the SRE, and that they answer every attitude question more positively (Cooke, 2002; Fournier \& Graves, 2002; Graves \& Liang, 2003). English language learners receiving the SRE also demonstrate superior ability in using higher order thinking skills.

With the rapid growth of computer technology, the concept of instructional scaffolding has been elaborated, related to CBI as another scaffolding tool to motivate EFL learners to read autonomously (Gunduz, 2005; Higgins, 1995). Thus, some printed texts are designed as hypertexts to help English language learners search for and comprehend the materials in a timely manner with computer-assisted functions (Iiyoshi et al., 2005; Wang et al., 2010). No matter whether reading a traditional printed text or a hypertext, it is essential to require EFL learners to do pre-, during-, and post-reading activities in a well-structured learning environment to motivate their interest in reading, guide their understanding, and synthesise the information contained within the text. According to Fitzgerald and Graves (2005), the framework of scaffolded reading can ease the cognitive demands on the English language learners by modelling, providing support with scaffolding, and gradually withdrawing support when EFL learners have mastered the skills for independent learning. Inspired by Vygotsky's (1978) zone of proximal development (ZPD) concept, which he defined as the distance between a child's "actual developmental level as determined by independent problem solving" and the higher level revealed in "potential development as determined through problem solving under adult guidance or in collaboration with more peers” (p. 86), it is important to provide a well-structured form of scaffolding for EFL readers to use background knowledge, words, and the acquisition of meaning by doing a series of pre-, during-, and post-reading activities until independent performance is achieved (Graves \& Graves, 2003; Pea, 2004).

\section{Comparison between print-based and hypertext reading}

Hypertexts are distinctly different from printed texts in ways that prompt readers to use unique cognitive processes and strategies (Coiro \& Dobler, 2007). According to Kasper (2003), reading hypertexts is a "naturally dynamic, recursive, and integrated process, one that provides multiple opportunities for students to acquire, test, and reframe knowledge through cognitive reconstruction of text, intertextual analysis and exposure to varied perspectives on issues” (p. 29). When reading hypertexts, readers must select a target location instead of turning the page, in order to move through the text (Coiro \& Dobler, 2007). Consequently, in comparison to printed texts, hypertexts require readers to take a much more active role in manipulating texts on screen as they adapt to the online reading environment for better reading comprehension (Gervais, 2007). 
A second difference is that contemporary hypertexts often incorporate navigation buttons or images "linked electronically by multiple paths, chains, or trails in an open-ended, perpetually unfinished textuality" (Landow, 1997, p. 3) to provide a visual representation of a hyperlink rather than a textual one. As described by Fitzgibbons (2008), the most basic property of hypertext is its capacity to create links within and among texts. Within a document, elements of the apparatus, such as definition of terms and references, can all be hyperlinked to provide readers with additional information for comprehension. Consequently, hypertext readers must integrate decoding processes and interpret images and pictures with their own comprehension strategies (Kinzer \& Leander, 2003). In other words, English language learners reading a hypertext must be able to identify what information is needed to enhance their specific comprehension of the topic and where to find that information via hyperlinking.

Finally, hypertexts differ dramatically from traditional texts in that they provide readers with the opportunity to interact with the text (Lawless et al., 2003). Hypertexts in particular provide new text formats and new ways to interact with information, which can help to extract meaning from traditional paper-based texts (Coiro, 2003). Hypertexts can be interactive and satisfy specific requirements of an EFL reader and allow readers to make decisions about what information to access (Landow, 1992; Moos \& Marroquin, 2010). Nevertheless, Gervais (2007) found that hypertext readers read quickly and are lost in the overflow of digital information.

\section{Research on hypertext reading and EFL reading comprehension}

With the advance of computer technology, researchers have begun to investigate the ways in which hypertexts could be employed to enhance students' reading comprehension. For over a decade, educational technologists have studied the uses and effects of hypertexts and have been centrally concerned with the role of hypertexts as a replacement for traditional printed texts (Eveland \& Dunwoody, 2002). Thus, numerous studies have been conducted in testing the unique contributions that hypertexts can make to the comprehension process, showing that students attain significantly higher comprehension scores by reading the hypertext version and that they also state a preference for that mode over the print version (Chen et al., 2011; Huang et al., 2009; MacArthur \& Haynes, 1995; Ray, 2004; Ray \& Belden, 2007). However, relatively few studies have reported the effect of hypertext reading on reading comprehension in the EFL context (Coiro \& Dobler, 2007; Huang, Chern, \& Lin, 2009). Although hypertexts can offer students many benefits, Rouet and Levonen (1996) advised that without overt scaffolding or intervention in how to navigate hypertexts effectively, students may become lost in a sea of information because reading hypertexts often requires a more cognitively demanding mode of learning than it does when reading printed texts (Nowak, 2008; Shapiro \& Niederhauser, 2004). Troffer's (2000) research showed that reading from the screen is about 30\% slower than reading from the printed text, and most hypertext readers tend to scan a document rather than read word for word. Liou (2004) also found that even though students in Taiwan have good computer literacy, they still have problems coping with electronic literacy due to a lack of appropriate strategies to comprehend online English texts.

Foltz (1996) investigated the role of prior knowledge, text structure, and coherence of hypertexts with respect to reading comprehension. He argued that hypertexts provide fewer context cues than the traditional printed texts. His study further indicated that lower proficiency readers need additional scaffolds with practice or a well-structured navigation system to maintain coherence within the hypertext and to assist in their comprehension of hypertext information. The well-structured scaffolded hypertext should contain the "human interaction" text (Al-Seghayer, 2005, p. 197). That is, the hypertext should provide English language readers with concise directions regarding how it is organised and connected with well-structured hyperlinks. A number of research results strongly suggest that students are confused by the less structured hypertext reading system, so the learning effect is decreased (Al-Seghayer, 2005; Shapiro \& Niederhauser, 2004). In the current study, a scaffolded hypertext reading system is defined as well-structured hypertext technology supports designed to augment EFL students' reading comprehension. Via doing pre-, during-, and post-reading activities in a well-structured hypertext system, it is assumed that EFL learners become aware of how and where to locate the necessary information with hyperlinks, thus acquiring the requisite amount of background and vocabulary knowledge to aid their comprehension of hypertext information (Lawless et al., 2003). 
Jacobson and Spiro (1996) also argued in their study that learners' beliefs play an important role during the process of hypertext reading, and students' attitudes and degree of satisfaction towards computers is an essential factor because it affects the success or failure of using a computer as an instructional tool. Hoffman (1998) investigated the effect and participants' perceptions of a hypertext environment on second language reading comprehension. Most of the participants indicated that reading hypertexts is not an easy task but it is faster. They also mentioned that their reading skills improved over the course of the 9-week study. Some participants perceived its richness, ease of access to information, and quickness of locating the target information positively, but at the same time, they expressed some concerns about the issue of disorientation and the complexity of the hypertext environment.

As discussed in the aforementioned studies, learners' psychological satisfaction or intrinsic motivation should be the ideal alternative measure of any e-learning systems since this would have significant effects on the learners' ongoing intention to use e-learning systems in the future (Katuk, Kim, \& Ryu, 2013; Lee, 2010; Lin, 2011). Davis's (1989) investigation focused on two theoretical constructs, perceived usefulness and perceived ease of use, which are fundamental determinants of system use. Perceived usefulness is defined as "the degree to which a person believes that using a particular system would enhance his or her job performance" (Davis, 1989, p. 320). Perceived ease of use refers to "the degree to which a person believes that using a particular system would be free of effort” (Davis, 1989, p. 320). Davis's research result indicates that perceived usefulness and perceived ease of use are significantly correlated with both self-reported current usage and self-predicted future usage. Alexander and Golja (2007) further examined that the very quality of the e-learning system is the user's learning experience or perception of usability (e.g., easy of use, effectiveness) and usefulness (i.e., learning performance). However, whether learning experience can correlate with learning performance is still open to question (Katuk et al., 2013). As such, the other focus of this study was to reveal how different perceived e-learning experiences (i.e., usefulness, ease of use, and attitude of future use) might relate to EFL reading comprehension performance. If EFL students have difficulties in understanding the text-based information, or students lose confidence and feel lost, they will suffer from anxiety or boredom in doing this hypertext activity (Csikszentmihalyi, 1990), so more structured scaffolding is needed for developing a more engaging e-learning hypertext system for autonomous learning (Katuk et al., 2013).

Since evidence of effective scaffolded hypertext reading on non-traditional EFL students' comprehension has been scarce, the purpose of this study is composed as follows:

(1) To investigate the difference in learning progress between teacher-guided print-based and hypertext reading environments;

(2) To compare non-traditional EFL students' attitudes within the contexts of teacher-guided print-based and hypertext reading interventions;

(3) To investigate the relationship between non-traditional EFL students' perceived e-learning experience (i.e., usefulness, ease of use, and attitude of future use) and their hypertext reading comprehension.

It is assumed that a significant difference between the teacher-guided print-based and hypertext interventions can be observed. If no obvious effect is found, it is essential to focus on the possible problems within the hypertext intervention in order to maximise non-traditional EFL students' reading outcomes.

\section{Methodology}

\section{Research design}

A single-group interrupted time-series quasi-experimental design was conducted to investigate a series of pre-observations (following teacher-guided print-based intervention) and post-observations (following hypertext intervention) on the reading score as the dependent variable for accuracy and stability of the data. In other words, this study was basically a pre- and post-test design with repeated observations before and after the treatment. To be more specific, the present study designed a hypertext reading system based on the works of Graves and Graves's (2003) SRE framework and Protopsaltis and Bouki's (2005) hypertext reading/comprehension model. A junior group and 14 observations in total before and after the scaffolding hypertext intervention as repeated pretests and posttests were conducted. 


\section{Subjects}

Twenty-eight non-traditional English majors (11 males and 17 females), who were approximately low-intermediate learners of English, from a junior reading class in fall 2013 at a private university in southern Taiwan participated in this study. The class was held in the evening because most of the Taiwanese non-traditional students worked at jobs. To ensure the non-traditional students' full participation, they were informed that doing this hypertext reading activity was part of the course requirements. Although the study began with 28 participants, enrolment changes and class absences resulted in complete comparison data for 23 original enrollees. A demographic questionnaire including age, gender, years of learning English reading, and self-evaluating English reading ability was administered to gather information about the subjects' backgrounds. Results from the questionnaires show that the subjects of this study ranged in ages from 20 to 57 years, with an average age of 27.5 years. More detailed demographic characteristics of the subjects are provided in Table 1.

Table 1

Sample characteristics

\begin{tabular}{lcc}
\hline Characteristic & $N$ & $\%$ \\
\hline Gender & & \\
$\quad$ Female & 13 & 56.5 \\
$\quad$ Male & 10 & 43.5 \\
\hline Years of learning English reading & & \\
1-3 years & 5 & 21.8 \\
4-6 years & 7 & 30.4 \\
7-10 years & 4 & 17.4 \\
$\quad$ More than 10 years & 7 & 30.4 \\
\hline Self-evaluated English reading ability & & \\
Excellent & 0 & 0 \\
Good & 5 & 21.8 \\
Fair & 12 & 52.2 \\
Not good & 5 & 21.8 \\
Poor & 1 & 4.2 \\
\hline
\end{tabular}

\section{Instruments}

\section{Materials}

Fourteen expository texts (about 500 words in each text) from the magazine English Digest were adopted for use in this study. The magazine consisting of low-intermediate learning is based on the General English Proficiency Test (GEPT) standards. The GEPT is a criterion-referenced test to assess language learners' general English proficiency in the listening, reading, writing, and speaking areas. At the start of 1999, the Ministry of Education in Taiwan commissioned the Language Training and Testing Center to develop a fair and reliable English test for all English learners at all levels of proficiency, consisting of five levels (i.e., elementary, intermediate, high-intermediate, advanced, and superior levels) (https://www.lttc.ntu.edu.tw/E_LTTC/E_GEPT.htm). In addition, the magazine has hired several well-known professors of English as language consultants and writers to ensure the top quality of the publication (http://www.english4u.net/web/about/about-english.aspx). Fourteen texts relating to what non-traditional EFL adults need in their daily life or work environments were selected according to a number of criteria: (a) they shared almost the same length, (b) they shared the same degree of difficulty, (c) they were authentic passages, (d) they were expository genre, and (e) they required general background knowledge to avoid misunderstanding of the text.

In order to carry out the study, 7 out of the 14 texts were randomly selected and designed by the researcher into a hypertext format. According to Puntambekar (1995) and Binder (1989), many factors should be taken into consideration in order to design a hypertext environment that facilitates learning, such as learning styles, intended audience, types of learning activities intended. Students reading a hypertext must be able to identify what information is needed to 
enhance their specific comprehension of the topic and where to find that information (Lawless et al., 2003). Thus, Harris, Mishra, and Koehler (2009) identified 42 distinct learning activity types and divided them into 13 knowledge-building and 29 knowledge-expression structures to facilitate students' understanding of the text. "Knowledge-building activity types are those in which students build content-related understanding through information-based process. Knowledge-expression activity types are those that help students deepen their understanding of content-related concepts using various types of communication” (Harris et al., 2009, p. 409). By adopting and integrating Harris et al.'s (2009) learning activity types, Protopsaltis and Bouki's (2005) hypertext reading/comprehension model, and Graves and Graves's (2003) SRE framework, the hypertext system designed and developed in the current study is composed of three main sections: introductory (pre-reading) section, text-based (during-reading) section, and monitoring (post-reading) section.

(1) The introductory section is to hyperlink encyclopedias for background knowledge or knowledge of the world. Readers are free to select various text-based information screens or media by following hyperlinks tagged with content headers.

(2) The text-based section is to direct students to link within and among texts. Within a document, elements of the scholarly apparatus, such as references, translation, vocabulary glossary with definitions and examples, are all hyperlinked to provide readers with additional information at the point of need (Fitzgibbons, 2008). It is through these links that lexias gain meaning and form the text as a whole (Carusi, 2006). In other words, this section would refer to the representation of the information by explaining the meaning of words, sentences, paragraphs, main ideas, and references to enhance readers' understanding of the text.

(3) The monitoring section is to assess learners' understanding of the text by asking text-based questions. As information in hypertext environments is presented in multiple segments, connected via hypertext links, readers have to recycle these same processes many times until they successfully accomplish the reading goal (Protopsaltis \& Bouki, 2005).

The flow chart and some screenshots for the designed hypertext reading system are illustrated in the following figures.

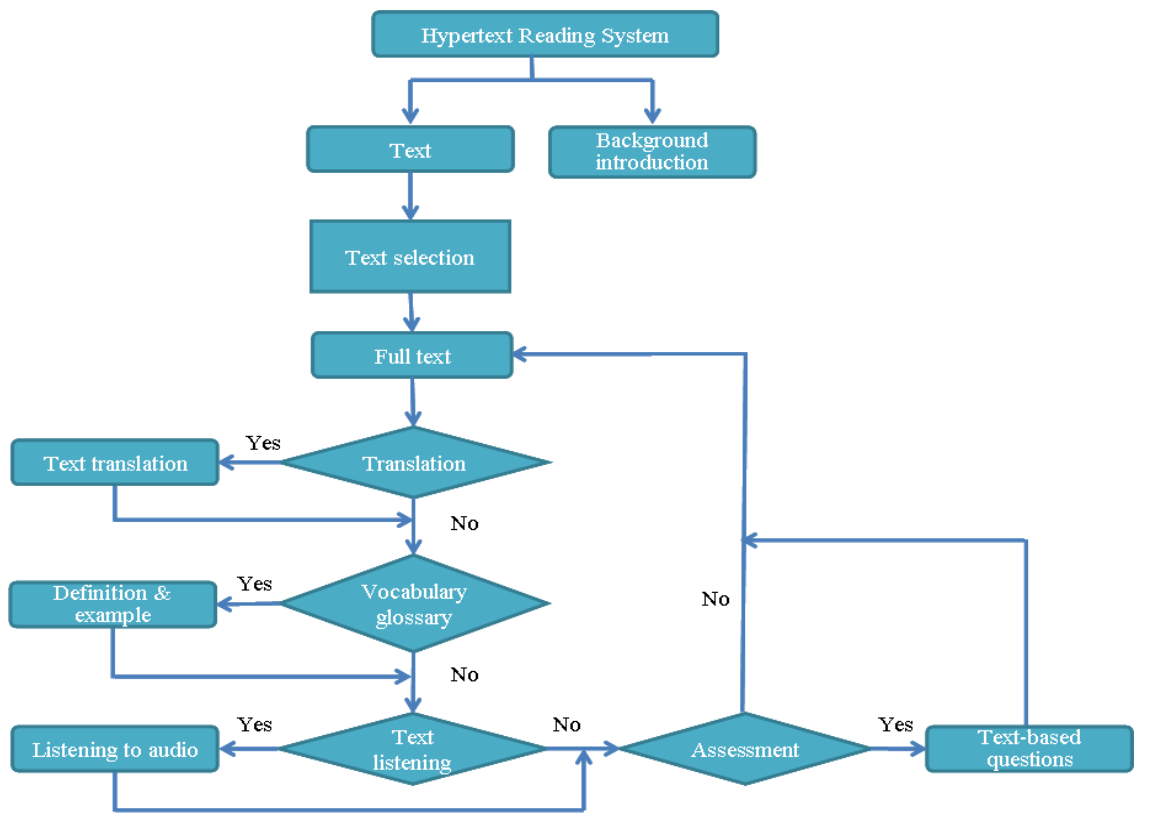

Figure 1. The conceptual flow chart of the hypertext design system 


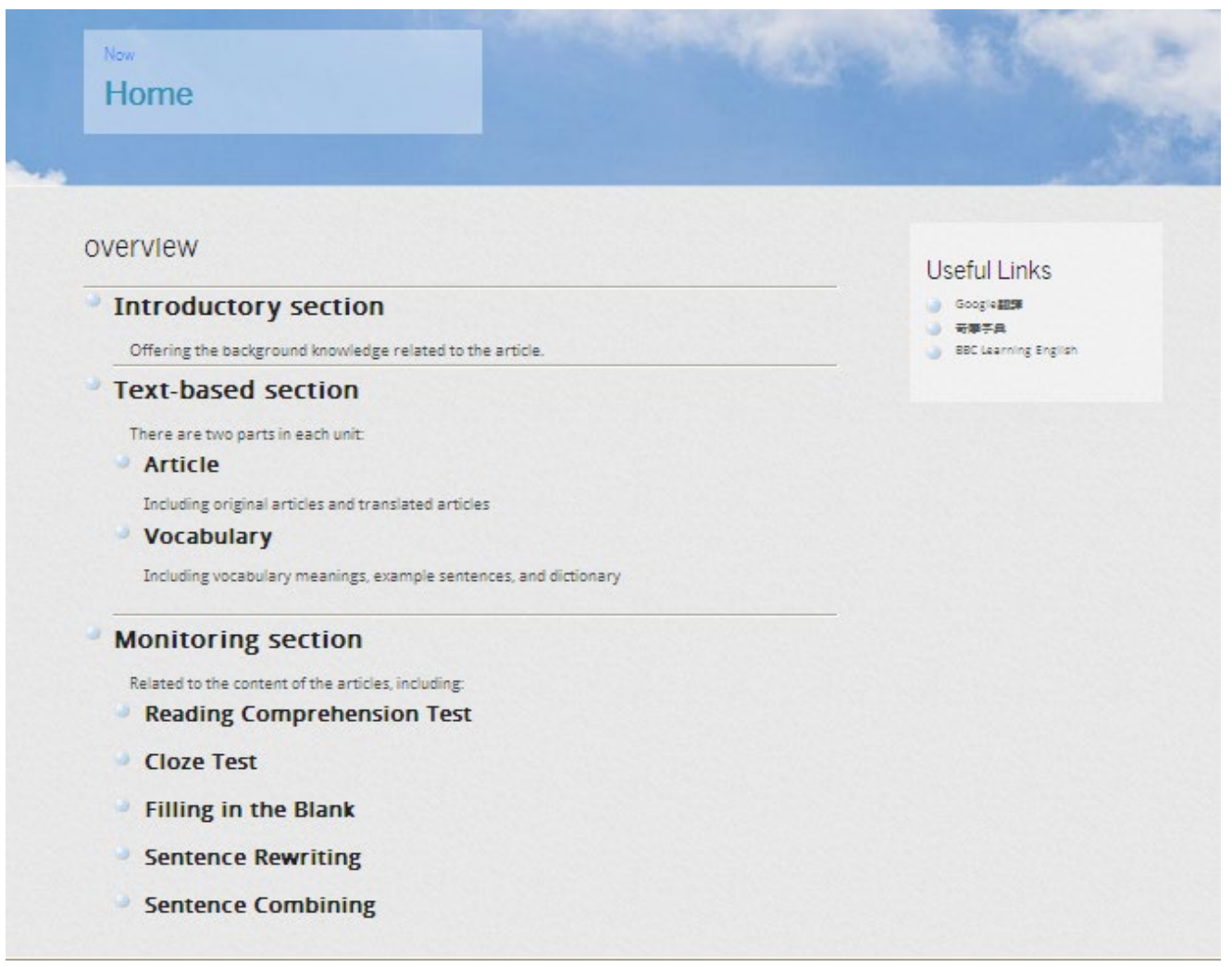

Figure 2. The interface of the hypertext system (http://140.127.208.97/program/)

\section{Unit 1 : Taiwanese Designer's Fashions fit For a First Lady}

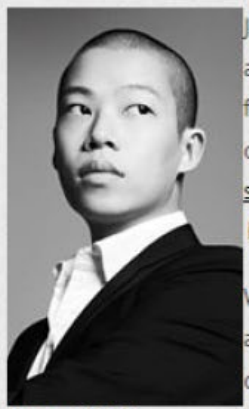

lason Wu may only be 26 years old, but the Taiwanese-born fashion designer has already seen his dresses donned by some highly visible and glamorous people. He found himself thrust into the limelight again when Michelle Obama wore one of his dresses to the 2013 inaugural ball. The Fisrt Lady is something of a Wu fanatic. sporting his haute couture during the President's first inauguration, on the cover of Vogue magazine, and on state visits to London to meet Queen Elizabeth II.

Vu, who was born in Taipei, was engrossed by fashion at an early age, and took to drawing sketches of wedding dresses he saw in Taipei shops. His mother noted his (Jason Wu) fascination and sent him to study in Vancouver, Canada to refine his drawing abilities. When he was 16 , Wu cold called the president of Integrity Toys, a company which made dolls, and sent them his sketches for potential doll clothing. Before long he was hired and promoted to creative director, designing dolls' outfits. Stint in Tokyo, Paris, and New York followedd as he went from creating miniature clothes to life-sized ensembles in 2006. Over the next few years he dressed the likes of Ivana Trump and notable drag queen RuPaul. It wasn't until 2008 that Michelle Obama discovered Wu's seemingly timeless design sensibilities. An editor at Vogue showed Obama Wu's work, which aroused her interest and soon she was sporting his clothes on television. This solidified what was arguably Wu's breakout moment in the fashion world. The young designer's dresses continue to grace red carpets and find their way into the wardrobes of

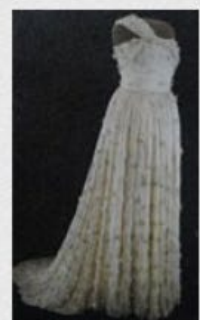

lickr by national
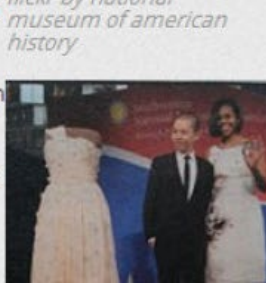

Useful Links

Google穋譯 奇库字典 BBC Learning English

Figure 3. A sample of a magazine article (adapted from English Digest, Unit 1, May 2013) 


\section{Content knowledge test}

A 10-item multiple-choice test to assess understanding of content knowledge was administered to the subjects after reading each text before and after the scaffolding intervention. One score for each subject was calculated. The maximum achievable score for each test was 10 to estimate students' reading comprehension. Fourteen test scores were collected before and after the scaffolding intervention serving as seven pretests (following the teacher-guided print-based instruction) and seven post-tests (following the hypertext reading). To evaluate content validity, two English instructors from the Department of English at the research site were invited to modify the test items to be more appropriate and content-based.

\section{A questionnaire}

A self-assessment questionnaire was adapted from Davis's (1989) technology acceptance model, Alexander and Golja's (2007) perceptions of usability and usefulness, as well as Csikszentmihalyi's (1990) flow experience theory to measure non-traditional EFL students' e-learning experience. Participants were asked to rate their learning experience in terms of teacher-guided print-based instruction and individual hypertext reading at the end of this experiment, using a 5-point Likert scale, ranging from 1 (strongly disagree) to 5 (strongly agree). The questionnaire, containing a total of 43 items, was composed of five constructs, comprising perceived usefulness of teacher-guided print-based instruction (8 items, $\alpha=.861$ ), confidence of reading ability after teacher's instruction (9 items, $\alpha=.822$ ), perceived usefulness of hypertext reading ( 8 items, $\alpha=.894$ ), perceived ease of hypertext use (9 items, $\alpha=.904$ ), and attitude and attempt of future hypertext use (9 items, $\alpha=.832$ ). In addition, three open questions were given in the questionnaire to explore students' hypertext learning experience in terms of encountering challenges, missing any feature or resource, as well as providing suggestions for improvement. A pilot study was conducted by five non-traditional juniors at the research site to ensure that each item was fully understandable. Students were clearly informed that there would be no assessment of their self-assessment learning experience. Examples of questionnaire items are provided in the appendix.

\section{Data collection procedures}

\section{Teacher-guided print-based intervention}

This study was conducted within the context of a reading course that meets once per week for 100-minute class periods throughout an 18-week semester in fall 2013. The reading course, Guided Reading (requirement/2 units), aimed at enhancing non-traditional students' reading comprehension in English. In the first seven weeks, 7 out of 14 expository texts were randomly selected for the instructor's scaffolding intervention, which was based on the SRE framework (Graves \& Graves, 2003). More specifically, three-phase face-to-face teacher-guided print-based reading activities were targeted for intervention in class for the goal of enhancing non-traditional EFL students' reading comprehension: (a) A pre-reading activity was used to activate students' background knowledge by asking students' general to specific questions as well as demonstrating how to locate the main ideas step by step through modeling. (b) A during-reading activity was developed to guide students to use multiple reading strategies, including understanding vocabulary, predicting reading content, identifying and skimming for the main idea, scanning for information and making inferences. (c) A post-reading activity was designed to monitor students' understanding by asking text-based questions, in order to help students discover the correct answers (Ritchey et al., 2012). The main purpose for the instructor, who was also the researcher, was to guide the EFL learners to read printed texts through such a comprehension intervention and help them to learn how to use various reading strategies effectively for their own independent hypertext reading afterwards. After each lesson intervention, a content knowledge test with 10 multiple-choice questions was immediately administered to the subjects. Students were required to finish the test in about 10-15 minutes. Figure 4 illustrates the process of the teacher-guided print-based reading intervention. 


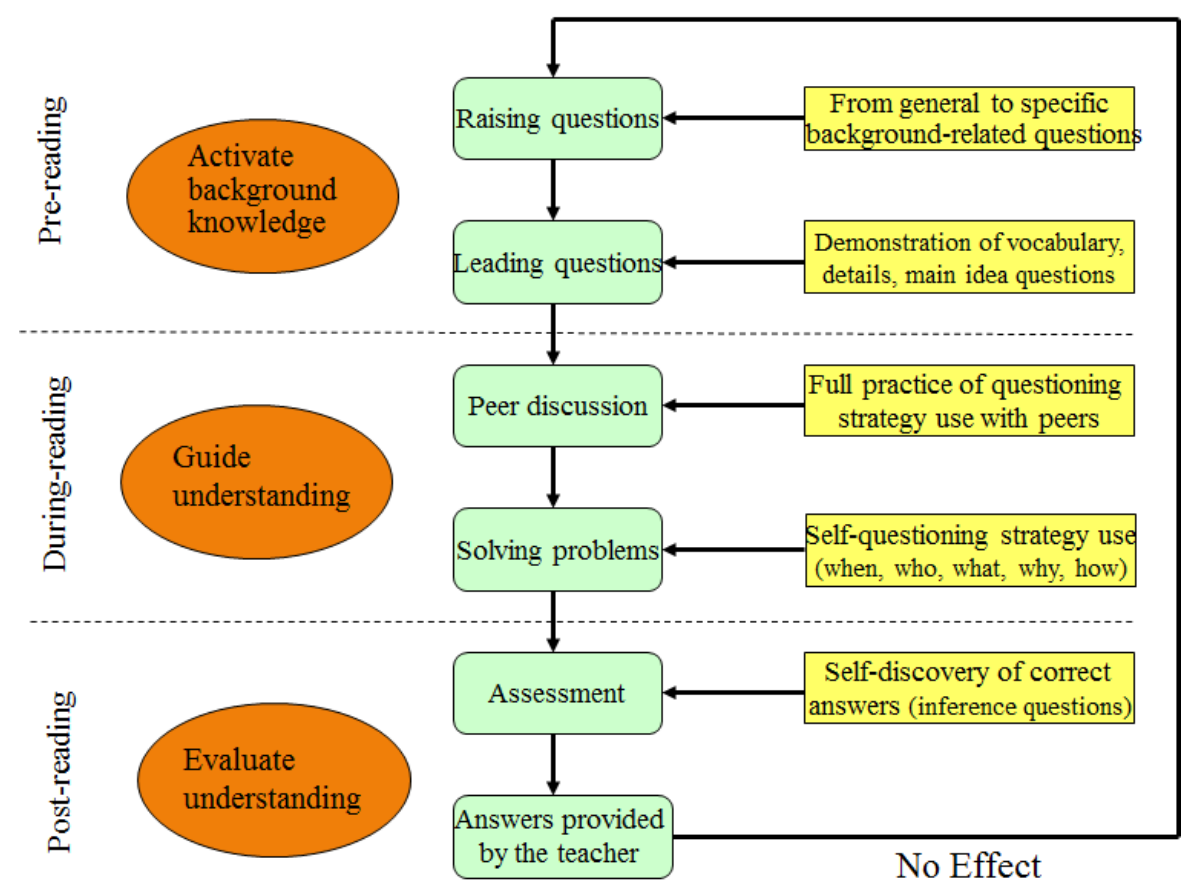

Figure 4. The flow chart of teacher-guided print-based reading intervention

\section{Hypertext intervention}

After the 7-week teacher-guided print-based reading intervention, the subjects were instructed on how to use the designed hypertext system step-by-step from their computer monitors and then they were asked to read the hypertext individually in front of a computer in the computer lab to display the document. Gillingham (1996) suggested that attention to text, task, and context is necessary for effective comprehension of hypertext; therefore, the instructions stressed that the subjects had to read the structured hypertext carefully in order to answer 10 multiple-choice text-based questions at the end of their individualised reading session. The post-intervention consisted of seven hypertexts to be implemented over 7 weeks. The intervention was provided in two 50-minute sessions per week. No attempts to teach reading comprehension were implemented during class periods, yet the students were free to take notes and were encouraged to ask questions at any time during the computer operation. Subjects would read the expository hypertext until they felt satisfied that they could answer 10 multiple-choice questions at the end of each session to assess their content knowledge comprehension. To avoid students checking the correct answers from the text, the instructor asked students to turn off the computer and answer the questions in written format on a piece of paper. The overall time-series quasi-experimental design is presented in Figure 5.

\section{Data analysis}

Differences between the pre- and post-scaffolding conditions were investigated by analysing pre/post-test differences and learning experience. More specifically, the purpose of this study was to (1) investigate the difference in learning progress across teacher-guided print-based and hypertext reading environments by analysing a series of pretest and post-test reading scores, (2) compare non-traditional EFL students' attitudes within the contexts of teacher-guided print-based and hypertext reading interventions, and (3) investigate the relationship between learners' perceived e-learning experience (i.e., usefulness, ease of use, and attitude of future use) and their hypertext reading comprehension. The first research question focused on how the data of a series of reading scores might look before and after the intervention, using a pair-sampled $t$-test to compare the mean differences. To answer the second research question, which sought to investigate non-traditional EFL students' self-reports in the survey of teacher-guided print-based instruction and individual hypertext reading, descriptive statistics were conducted. For the third research 
question (the relationships among perceived usefulness, perceived ease of use, and attitude of future use in the survey of the students' e-learning experience on hypertext comprehension scores), a series of bivariate correlations were conducted.

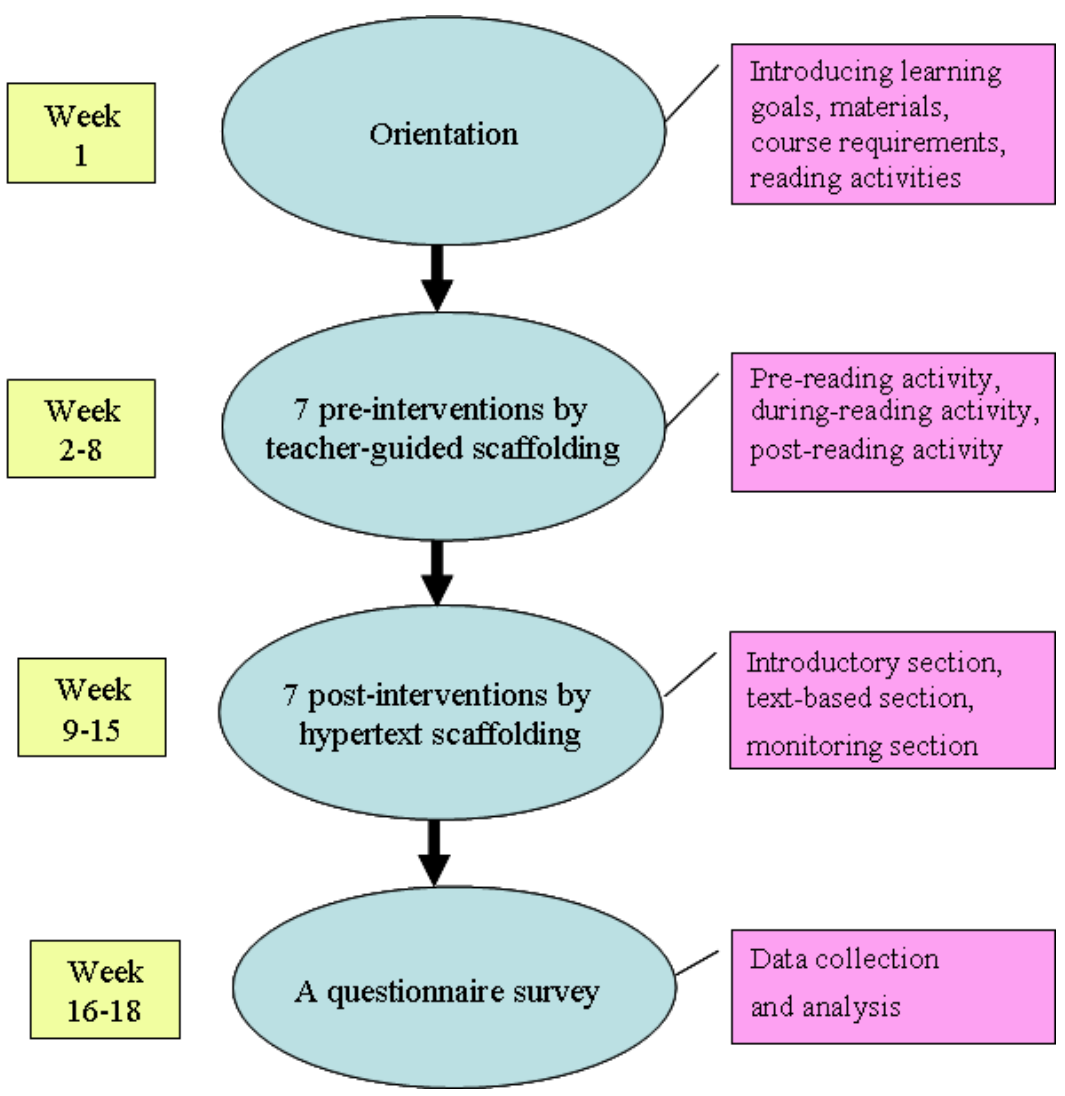

Figure 5. The flow chart of the time-series quasi-experimental design

\section{Results}

\section{Learning progress}

Seven pre-intervention scores for the teacher-guided print-based reading activities were compared to seven post-intervention scores for the hypertext activities. The actual means and standard deviations of the student scores in the pre- and post-test for each of the 14 activities are listed in Table 2. In the first 7 weeks conducted by the teacher-guided print-based reading instruction, students' mean scores ranged from 6.50 to 8.38 , with a mean pre-intervention score of $7.39(S D=2.97)$. Regarding students' hypertext reading performance from weeks 8 to 14, the mean scores ranged from 6.40 to 8.63, with a mean post-intervention score of $7.51(S D=2.83)$. A pair-sampled $t$-test was further conducted, and revealed no significant difference $(p>.05)$ in comprehension between the teacher-guided print-based and hypertext intervention conditions. There appears to be no obvious improvement from pre- to post-test scores, which indicates that both teacher-guided print-based and hypertext interventions might be effective in helping non-traditional EFL students in their reading. 
Table 2

Means and standard deviations of the pre- and post-test scores

\begin{tabular}{|c|c|c|c|c|}
\hline & Mean & $S D$ & $t$ & $p$ \\
\hline \multicolumn{5}{|c|}{ Pre-test scores } \\
\hline Test 1 & 7.30 & 2.13 & \multirow{17}{*}{.557} & \multirow{17}{*}{.582} \\
\hline Test 2 & 6.59 & 2.42 & & \\
\hline Test 3 & 7.68 & 2.34 & & \\
\hline Test 4 & 8.38 & 1.24 & & \\
\hline Test 5 & 8.11 & 2.19 & & \\
\hline Test 6 & 7.15 & 2.80 & & \\
\hline Test 7 & 6.50 & 3.02 & & \\
\hline Total & 7.39 & 2.97 & & \\
\hline \multicolumn{3}{|c|}{ Post-test scores } & & \\
\hline Test 8 & 7.71 & 1.57 & & \\
\hline Test 9 & 7.71 & 1.63 & & \\
\hline Test 10 & 7.88 & 1.70 & & \\
\hline Test 11 & 8.63 & 1.64 & & \\
\hline Test 12 & 7.30 & 2.20 & & \\
\hline Test 13 & 6.40 & 2.66 & & \\
\hline Test 14 & 6.92 & 2.94 & & \\
\hline Total & 7.51 & 2.83 & & \\
\hline
\end{tabular}

Figure 6 further highlights progress monitoring measures across 14 time points with 14 mean scores. By observing the trend line, the outcome measure increased immediately after the hypertext intervention and then it was stable at a certain level; however, it returned to the pre-intervention baseline. Though the upward trend initially evident after the hypertext intervention was not sustained, the post-test scores $(M=$ 7.51) were slightly higher compared with the pre-test scores $(M=7.39$ ) (see Table 2). To further investigate the mean improvement from pre-test (teacher-guided print reading) to post-test (hypertext reading) scores for the two learning conditions, an ANCOVA technique was applied to neutralise the effect of the pre-test variable. In other words, to control the effect of pre-test performance, the score on the pre-test was used as a covariant and the score on the post-tests of the two groups were compared. After the pre-test performance was removed, a significant mean improvement from pre- to post-test scores was found, $F(1,25)=58.42, p<.05$. This was statistically significant after the hypertext intervention, suggesting that hypertext activities may play a role in responsiveness to comprehension performance.

Since both $t$-test and ANCOVA results were not exactly the same, more questionnaire analyses are required to thoroughly explore non-traditional EFL students' attitudes towards the effect of the teacher-guided print-based and hypertext learning conditions.

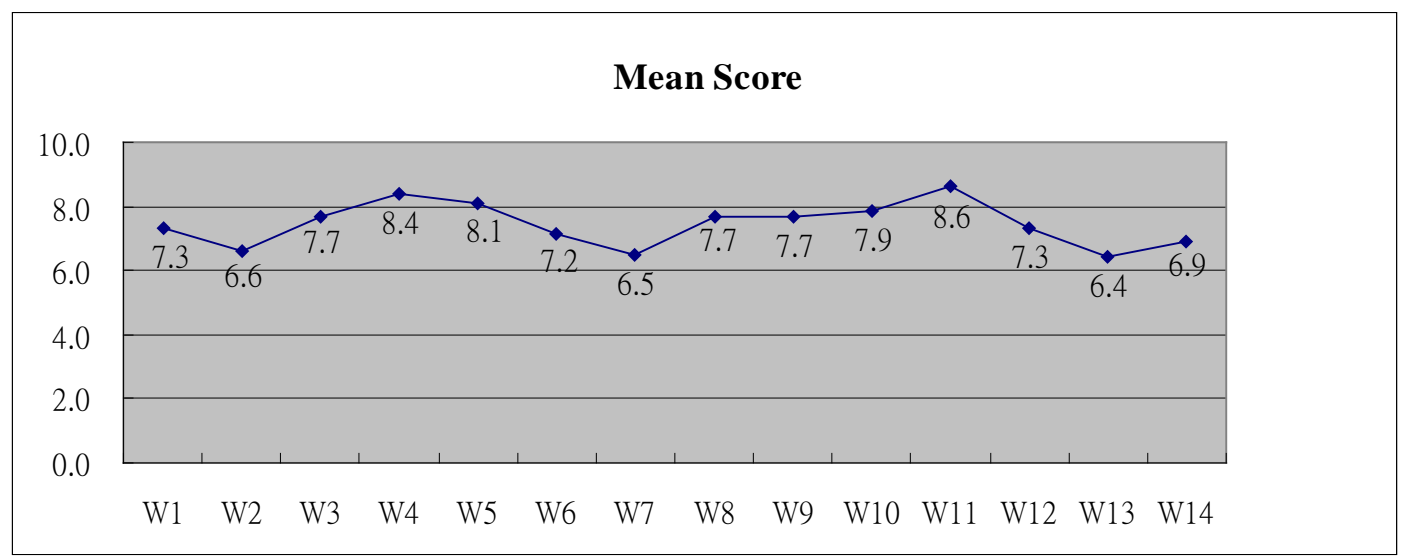

Figure 6. Overall growth of 14-week intervention 


\section{Students' attitudes towards teacher-guided print-based and hypertext interventions}

Descriptive statistics for each questionnaire mean, ranging from 3.12 to 4.43 are shown in the appendix. The five constructs, arranged with means in descending order, are ease of hypertext use $(M=4.00)$, usefulness of teacher-guided print-based instruction $(M=3.88)$, usefulness of hypertext reading $(M=$ 3.86), confidence of reading ability after teacher's instruction $(M=3.80)$, and future hypertext use $(M=$ 3.77).

To be more specific to highlight the obvious effect toward these two intervention conditions, $77.0 \%$ of the subjects reported that via teacher's instruction, they understood the importance of using appropriate reading strategies in reading process $(M=4.08, S D=.744) ; 84.7 \%$ could catch the main idea of the text $(M=4.31, S D=.736) ; 84.6 \%$ learned the knowledge of the text via teacher's explanations $(M=4.12, S D$ $=.766)$, and $88.4 \%$ agreed that they could understand the content by teacher's helpful explanations $(M=$ $4.23, S D=.652$ ). Generally speaking, $76.9 \%$ of the subjects did not feel wasting time in class due to teacher's explicit instruction $(M=4.31, S D=.838)$.

In addition to students' positive feedback toward teacher-guided instruction for better understanding the content of the printed text, the majority of subjects also supported the benefits of individual hypertext reading. For example, $73.9 \%$ of the subjects reported that using this designed hypertext system enhanced their effectiveness on reading tasks $(M=4.04, S D=.767)$. Regarding the ease of hypertext use, $69.6 \%$ did not feel confused while using this system $(M=4.04, S D=.824)$, nor consult with the teacher about how to use it $(M=4.22, S D=.902)$. Generally speaking, $86.9 \%$ of the students did not find it difficult to use this e-learning system $(M=4.43, S D=.728)$. Overall, $78.2 \%$ believed that using this designed hypertext system would be free of effort $(M=4.13, S D=.869)$, and $91.3 \%$ did not suffer from boredom while doing the online reading tasks $(M=4.22, S D=.600)$. Based on the questionnaire results, the subjects generally perceived the usefulness of employing both the teacher-guided print-based and hypertext interventions to enhance their reading comprehension. Such a finding is consistent with the $t$-test result, showing that there was no significant difference in comprehension between reading scores before and after the hypertext intervention.

Apart from the positive effects reported by the students of using the designed hypertext system, a minority of subjects expressed that they still preferred reading the printed text as an orderly succession of ideas from which they could easily obtain the contextual cues. Besides, students perceived that they could not grasp information more fully when it is presented in a network; part of the reason is that reading the text on the computer screen hurt their eyes, particularly for some older non-traditional students; the other reason is that they were unable to identify the necessary information due to a lack of sufficient prior knowledge, so that they got lost in the hypertext reading.

\section{The relationship between hypertext learning experience and reading score}

To examine the relationship between the hypertext learning experience (i.e., perceived usefulness of hypertext reading, perceived ease of hypertext use, and attitude and attempt of future hypertext use) on reading comprehension score, a zero-order correlation was conducted for the purpose of this study. To minimise the number of variables to be included, only the mean of the hypertext intervention score was used. The results in Table 3 indicate that the three constructs of students' hypertext experience were significantly correlated with each other (correlation coefficients ranged from .54 to $.80, p<.01$ ). There appears to be a significantly strong and positive relationship $(r=.80, p=.00)$ between the perceived usefulness of hypertext reading and the attempt of future hypertext use, suggesting a significant relationship of perceptions of usefulness of hypertext reading on future hypertext usage. However, no significant relationship was observed between the e-learning experience and the hypertext reading score, which suggests the relationship between hypertext learning experience and reading comprehension performance was the weakest. 
Table 3

The relationship among usefulness, ease, and attitude of future hypertext use on hypertext score

\begin{tabular}{|c|c|c|c|c|}
\hline the & Usefulness & Ease & Future use & Hypertext score \\
\hline $\begin{array}{l}\text { Usefulness } \\
\quad r \\
\text { Sig. } \\
\end{array}$ & 1 & & & \\
\hline $\begin{array}{l}\text { Ease } \\
r \\
\text { Sig. } \\
\end{array}$ & $\begin{array}{l}.640 * * \\
.001 \\
\end{array}$ & 1 & & \\
\hline $\begin{array}{l}\text { Future use } \\
r \\
\quad \text { Sig. } \\
\end{array}$ & $\begin{array}{l}.795^{* *} \\
.000 \\
\end{array}$ & $\begin{array}{l}.538 * * \\
.008\end{array}$ & 1 & \\
\hline $\begin{array}{l}\text { Hypertext score } \\
r \\
\quad \text { Sig. } \\
\end{array}$ & $\begin{array}{l}.089 \\
.686 \\
\end{array}$ & $\begin{array}{l}.347 \\
.105 \\
\end{array}$ & $\begin{array}{l}.048 \\
.828 \\
\end{array}$ & 1 \\
\hline
\end{tabular}

$* * p<.01$.

\section{Discussion and conclusion}

The purpose of this study was to determine if a 14-week teacher-guided print-based and hypertext reading intervention that focused on comprehension of expository text affected non-traditional EFL students' reading comprehension and probability of reading problems within a hypertext environment. The results of this quasi-experimental study are not absolutely optimistic. The primary finding of this investigation reveals that a 7-week hypertext intervention was not significantly effective in comparison with teacher-guided print-based reading instruction, though a significant mean improvement was found after hypertext learning. To get a complete picture of students' pre- to post-learning conditions, it is essential to focus on the questionnaire findings, which were the only reliable outcome found regarding the benefits and drawbacks of hypertext intervention.

The finding that aspects of non-traditional EFL students' perceived hypertext learning experience (i.e., usefulness, ease, and future usage) were significantly correlated with each other, is consistent with Davis's (1989) research finding, indicating that perceived usefulness and perceived ease of use are significantly correlated with self-predicted future usage. Based on the non-traditional EFL students' self-reports of hypertext learning experiences, they believed that they should have control in operating the designed hypertext system because most of them did not find it difficult to use this e-learning system, which shows that they perceived an improvement in their hypertext reading performance due to their accomplishing the reading tasks more quickly and easily. In addition, a significantly strong and positive correlation was found between the usefulness of hypertext reading and attempt of future usage, suggesting that the majority of students intended to use the hypertext system in their future reading, but that the degree of usefulness of hypertext reading was not reliably predicted by their hypertext comprehension scores. Although research has clearly illustrated that individual hypertext reading can positively impact reading comprehension (Chen et al., 2011; Huang et al., 2009; MacArthur \& Haynes, 1995; Ray, 2004; Ray \& Belden, 2007), the current investigation did not identify a significant relationship between hypertext reading and reading achievement. As such, it is important to explore the drawbacks of hypertext reading.

Some students argued that the designed hypertexts provide fewer orderly context cues than traditional printed texts. Charney (1994) claimed that one of the challenges that leads students to not read online is that when reading in a hypertext environment they face the problem of missing contextual cues. That is, readers may find navigation becomes arbitrary through a lack of clues to the meaning of links between nodes. Consequently, students would like to read traditional printed texts because they can cohesively and effectively use contextual clues in sentences and paragraphs to help them create inferences that aid in text understanding (Lawless et al., 2003).

Furthermore, some students indicated that they had become lost in hypertext reading due to eyestrain. Troffer (2000) stated that screen glare and screen reading can possibly cause eyestrain which impairs 
hypertext reading. Gleaves (2003) has pointed out that it is, therefore, essential to design a hypertext environment by providing a visible index to the content for successful learning experiences. Besides, lack of the prerequisite amount of prior knowledge is another problem reported by the non-traditional EFL students. Such a research result aligns with the findings of Nowak (2008) and Shapiro and Niederhauser's (2004) studies, suggesting that students who do not possess a prerequisite amount of domain knowledge may get lost in the hypertext, and be unable to identify or locate necessary information. Foltz (1996) proposed that lower proficiency readers particularly need additional scaffolds to maintain coherence within the hypertext and to aid them in their comprehension of hypertext information. Therefore, teachers and classmates, for example, should support student learning with authentic tasks by modelling what information is needed and where to find that information, by providing support with scaffolding, and gradually withdrawing support when learners have mastered the reading skills needed to enhance their specific comprehension of the topic (Brown, Collins, \& Duguid, 1989; Lawless et al., 2003).

Since a statistically significant gain from pre- and post-reading comprehension scores was not observed, it is reasonable to note that teacher-guided print-based reading instruction that targets vocabulary, background knowledge, and comprehension skills is important for poor non-traditional EFL readers, because of evidence suggesting that poor readers exhibit multiple reading problems, such as weakness in word recognition, prior knowledge, and effective reading strategy use (Salmerón, Kintsch, \& Cañas, 2006; Shang, 2010). Part of the reason is that poor Taiwanese readers normally employ low-level or local processing strategies when they read the English texts (Cheng, 2000). Thus, a focus on teacher-scaffolded print-based reading intervention provides an opportunity for poor non-traditional EFL readers to learn the content of the text through the instructor's explicit explanations with the primary goal of improving reading comprehension.

\section{Limitations and future research}

In this study, an e-learning hypertext system was designed and developed to examine if hypertext interventions could affect non-traditional EFL students' reading comprehension. Due to the research finding of no significant relationship between hypertext reading and reading achievement, the present study suffers from several limitations.

First, the hypertext system designed in the current study was developed to hyperlink encyclopedias and references to build up EFL learners' background knowledge or knowledge of the world with additional information for comprehension, but there is little evidence to figure out how students build sequences of information within a hypertext, nor how they navigate hypertexts. Besides, much less is known about whether the teacher scaffolding provided in the first half of the print-based intervention may have had an impact on the EFL students' reading performance during the hypertext activities in the second half of the intervention.

Prior literature on hypertext comprehension has claimed that hypertext could improve learning more than a linear version of the text; the benefit of hypertext reading lies in whether learners can use effective strategies in reading hypertexts (Dillon \& Gabbard, 1998; Salmerón et al., 2006; Unz \& Hesse, 1999). Lawless et al.'s (2003) study found that individuals select and sequence information differently; higher-proficiency learners seem to use more efficient reading strategies when operating in a linear hypertext environment than lower-proficiency learners. Except for a lack of the appropriate strategy use, EFL readers may also find the online English texts difficult to comprehend due to their low proficiency level, though students in Taiwan have good computer literacy (Liou, 2004). Future research should, therefore, examine the impact and relationship among the variables of reading strategy use, English proficiency level, and hypertext comprehension, particularly focusing on how to train low-proficiency learners to have sufficient prior knowledge by using efficient and effective strategies for reading and comprehending hypertexts.

The second limitation of the study is its external validity. Any discussion of quasi-experimental measures should recognise that there will always be a question of generalisability of findings when they do not include broader measures. This study, for instance, did not use randomly selected participants, had a relatively small sample size and included a relatively high loss rate of participants who started in this reading course. Future investigation is needed to examine a larger group of participants to better 
understand different proficiency students' approaches to hypertext reading in foreign language classrooms.

Finally, the present study is also limited by the length of the hypertext intervention. Kasper's (2003) study found significant effects for hypertext intervention delivered over an approximately 2-year intervention, much longer than the current study. It seems sensible that students can not capture growth, especially when interventions are of short-term duration. More research is obviously needed to identify the ideal length of the intervention on hypertext reading comprehension. A longitudinal study across years may be one way to untangle these critical outcomes.

However, given the limitations of this study, the designed hypertext system has the potential to accomplish the goal of facilitating students' ongoing intention to use the e-learning system outside the class in their free time, which is especially important for non-traditional EFL students who have jobs during the daytime. Such a new learning strategy should also provide an avenue for EFL students to gain a greater understanding of different reading materials via online learning. Most importantly, the designed hypertext system can help non-traditional EFL learners enhance their reading skills, related computer knowledge, as well as motivation for autonomous learning. In this way, both EFL reading instructors and students can be empowered to use hypertext to its full advantage.

\section{Acknowledgements}

This work was supported by the National Science Council (NSC 102-2410-H-214 -016).

\section{References}

Alexander, S., \& Golja, T. (2007). Using students’ experiences to derive quality in an e-learning system: An institution's perspective. Educational Technology \& Society, 10, 17-33. Retrieved from http://www.ifets.info/journals/10_2/3.pdf

Alfassi, M. (2004). Reading to learn: Effects of combined strategy instruction on high school students. Journal of Educational Research, 97(4), 171-184. doi:10.3200/JOER.97.4.171-185

Alkhalifa, E. (2008). The effects of using a bulletin board on gender differences in program coding. AACE Journal, 16(2), 95-114. Retrieved from http://www.editlib.org/d/24256

Al-Seghayer, K. (2005). ESL readers' perceptions of reading in well structured and less structured hypertext environments. CALICO Journal, 22(2), 191-212. Retrieved from http://www.equinoxpub.com/journals/index.php/CALICO/article/view/23183

Anderson-Inman, L., Horney, M., Der-Thanq, C., \& Larry, L. (1994). Hypertext literacy: Observations from the Electro text project. Language Arts, 71, 279-289. Retrieved from http://www.jstor.org/stable/41961966

Astleitner, H., \& Steinberg, R. (2005). Are there gender differences in web-based learning? An integrated model and related effect sizes. AACE Journal, 13(1), 47-63. Retrieved from http://www.editlib.org/d/18902/

Barnett, M. A. (1989). More than meets the eye. Englewood Cliffs, NJ: Prentice Hall Regents.

Binder, C. (1989). Hypertext design issues. Performance Improvement Quarterly, 2(3), $16-33$. doi:10.1111/j.1937-8327.1989.tb00409.x

Brown, J. S., Collins, A., \& Duguid, P. (1989). Situated cognition and the culture of learning. Educational Researcher, 18(1), 32-42. doi:10.3102/0013189X018001032

Carusi, A. (2006). A comparison of hypertext theory and phenomenology of reading. Arts \& Humanities in Higher Education, 5(2), 163-180. doi:10.1177/1474022206063652

Chang, R. (1998). Strategies for reading English as a foreign language (Unpublished doctoral dissertation). State University of New York.

Charney, D. (1994). The effect of hypertext on processes of reading and writing. In C. L. Selfe \& S. Hilligoss (Eds.), Literacy and computers: The complications of teaching and learning with technology (pp. 238-263). New York, NY: Modern Language Association.

Chen, N. S., Teng, D. C. E., Lee, C. H., \& Kinshuk. (2011). Augmenting paper-based reading activity with direct access to digital materials and scaffolded questioning. Computers \& Education, 57, 1705-1715. doi:10.1016/j.compedu.2011.03.013 
Cheng, C. K. (1998). A descriptive study of reading strategies used by Chinese ESL students from Taiwan (Unpublished doctoral dissertation). University of Kansas.

Cheng, C. K. (2000, May). The relationship between four metacognitive factors and reading ability. Proceedings of the 17th International Conference on English Teaching and Learning in the Republic of China (ROC-TEFL) (pp. 277-293). Taiwan: Soochow University.

Coiro, J. L. (2003). Reading comprehension on the Internet: Expanding our understanding of reading comprehension to encompass new literacies. The Reading Teacher, 56, 458-464.

Coiro, J. L., \& Dobler, E. (2007). Exploring the online reading comprehension strategies used by sixth-grade skilled readers to search for and locate information on the Internet. Reading Research Quarterly, 42(2), 214-257. doi:10.1598/RRQ.42.2.2

Cooke, C. L. (2002, December). The effects of scaffolding multicultural short stories on students' comprehension and attitudes. Paper presented at the 51st Annual Meeting of the National Reading Conference, Miami.

Csikszentmihalyi, M. (1990). Flow: The psychology of optimal experience. New York, NY: Harper \& Row Publishers.

Davis, F. D. (1989). Perceived usefulness, perceived ease of use, and user acceptance of information technology. MIS Quarterly, 13(3), 319-339. doi:10.2307/249008

Dillon, A., \& Gabbard, R. (1998). Hypermedia as an educational technology: A review of the quantitative research literature on learner comprehension, control, and style. Review of Educational Research, 68, 322-349. doi:10.3102/00346543068003322

Dole, J. A., Duffy, G. G., Roehler, L. R., \& Pearson, P. D. (1991). Moving from the old to the new: Research on reading comprehension instruction. Review of Educational Research, 61(2), 239-264. doi:10.3102/00346543061002239

Eveland, W. P., \& Dunwoody, S. (2002). An investigation of elaboration and selective scanning as mediators of learning from the web versus print. Journal of Broadcasting \& Electronic Media, 46(1), 34-53. doi:10.1207/s15506878jobem4601_3

Fitzgerald, J., \& Graves, M. F. (2005). Reading supports for all. Educational Leadership, 62(4), 68-71.

Fitzgibbons, M. (2008). Implications of hypertext theory for the reading, organization, and retrieval of information. Library Philosophy and Practice. Retrieved from http://unllib.unl.edu/LPP/fitzgibbons.htm

Foltz, P. W. (1996). Comprehension, coherence, and strategies in hypertext and linear text. In J. F. Rouet, J. J. Levonen, A. Dillon, \& R. J. Spiro (Eds.), Hypertext and cognition (pp. 109-136). Mahwah, NJ: Lawrence Erlbaum.

Fournier, D. N. E., \& Graves, M. F. (2002). Scaffolding adolescents' comprehension of short stories. Journal of Adolescent and Adult Literacy, 40, 30-39.

Gervais, B. (2007). Is there a text on this screen? Reading in an era of hypertextuality. In R. Siemens \& R. Schreibman (Eds.), A companion to digital literary studies (pp. 183-202). Malden, MA: Blackwell.

Gillingham, G. M. (1996). Comprehending electronic text. In H. van Oostendorp \& S. de Mul (Eds.), Cognitive aspects of electronic text processing (pp. 77-98). New York, NY: Ablex Publishing.

Gleaves, E. S. (2003). The future of books and libraries in an age of hyperlinks. Against the Grain, 14(6), 38-40.

Graves, M. F., \& Graves, B. B. (2003). Scaffolding reading experience: Designs for student success (2nd ed.). Norwood, MA: Christopher-Gordon Publishers.

Graves, M. F., \& Liang, L. A. (2003). On-line resources for fostering understanding and higher-level thinking in senior high school students. In D. L. Schallert, C. M. Fairbanks, J. Worthy, B. Maloch, \& J. V. Hoffman (Eds.), 51st yearbook of the National Reading Conference (pp. 204-215). Oak Creek, WI: National Reading Conference.

Gunduz, N. (2005). Computer assisted language learning. Journal of Language and Linguistic Studies, 1(2), 193-214. Retrieved from http://www.jlls.org/index.php/jlls/article/view/16

Harris, J., Mishra, P., \& Koehler, M. (2009). Teachers' technological pedagogical content knowledge and learning activity types: Curriculum-based technology integration reframed. Journal of Research on Technology in Education, 41(4), 393-416. doi:10.1080/15391523.2009.10782536

Higgins, J. (1995). Computers and English language learning. London: Intellect Ltd.

Hoffman, S. (1998). The effect of a hypertext environment on the reading comprehension of second language learners in an intermediate-level college German course (Unpublished doctoral dissertation). University of South Alabama, AL.

Huang, H. C., Chern, C. L., \& Lin, C. C. (2009). EFL learners' use of online reading strategies and 
comprehension of texts: An exploratory study. Computers \& Education, 52, 13-26. doi:10.1016/j.compedu.2008.06.003

Iiyoshi, T., Hannafin, M. J., \& Wang, F. (2005). Cognitive tools and student-centered learning: Rethinking tools, functions and applications. Educational Media International, 42(4), 281-296. doi:10.1080/09523980500161346

Jacobson, M., \& Spiro, R. (1996). Hypertext learning environments, cognitive flexibility, and the transfer of complex knowledge: An empirical investigation (Report No. CSR-TR-573). Urbana, IL: Office of Educational Research and Improvement.

Kasper, L. F. (2003). Interactive hypertext and the development of ESL students' reading skills. The Reading Matrix, 3(3). Retrieved from http://www.readingmatrix.com/articles/kasper/index2.html

Katuk, N., Kim, J., \& Ryu, H. (2013). Experience beyond knowledge: Pragmatic e-learning systems design with learning experience. Computers in Human Behavior, 29, 747-758. doi:10.1016/j.chb.2012.12.014

Kim, M. C., \& Hannafin, M. J. (2011). Scaffolding problem solving in technology-enhanced learning environments (TELEs): Bridging research and theory with practice. Computers \& Education, 56(2), 403-417. doi:10.1016/j.compedu.2010.08.024

Kinzer, C., \& Leander, K. (2003). Technology and the language arts: Implications of an expanded definition of literacy. Retrieved from http://www.studyplace.org/wiki/Kinzer_and_Leander_Lecture

Ko, M. (2002). A study on teachers' perception of strategy use: Reading strategy instruction and students’ motivation to read. Journal of National Huwei Institute of Technology, 5, 202-212.

Landow, G. P. (1992). Hypertext: The convergence of contemporary theory and technology. Baltimore, MD: Johns Hopkins University Press.

Landow, G. P. (1997). Hypertext 2.0. Baltimore, MD: Johns Hopkins University Press.

Lawless, K. A., Brown, S. W., Mills, R., \& Mayall, H. J. (2003). Knowledge, interest, recall and navigation: A look at hypertext processing. Journal of Literacy Research, 35(3), 911-934. doi:10.1207/s15548430jlr3503_5

Lawless, K. A., \& Kulikowich, J. M. (1996). Understanding hypertext navigation through cluster analysis. Journal of Educational Computing Research, 14(4), 385-399. doi:10.2190/DVAP-DE23-3XMV-9MXH

Lee, M. C. (2010). Explaining and predicting users' continuance intention toward e-learning: An extension of the expectation-confirmation model. Computers \& Education, 54, 506-516. doi:10.1016/j.compedu.2009.09.002

Li, D. D., \& Lim, C. P. (2008). Scaffolding online historical inquiry tasks: A case study of two secondary school classrooms. Computers \& Education, 50(4), 1394-1410. doi:10.1016/j.compedu.2006.12.013

Liang, L. J., \& Lai, C. H. (2003). The research of learning motivation and learning strategies of night school students in junior colleges. Journal of Education and Psychology, 26, 717-748.

Lin, K. M. (2011). E-learning continuance intention: Moderating effects of user e-learning experience. Computers \& Education, 56, 515-526. doi:10.1016/j.compedu.2010.09.017

Liou, H. C. (2004). Critical issues of ELT and e-learning in the 21st century. Paper presented at the ELT and E-learning in an electronic age: Issues and alternative, Tamkang University, Taiwan, ROC.

MacArthur, C. A., \& Haynes, J. B. (1995). Student assistant for learning from text (SALT): A hypermedia reading aid. Journal of Learning Disabilities, 28, 150-159. doi:10.1177/002221949502800304

Moos, D. C., \& Marroquin, E. (2010). Multimedia, hypermedia, and hypertext: Motivation considered and reconsidered. Computers in Human Behavior, 26, 265-276. doi:10.1016/j.chb.2009.11.004

Nowak, L. (2008). Digital reading theory and its relationship to academic reading practices. Design of Electronic Text, 1(1), 1-7.

Paris, S. G., \& Oka, E. R. (1989). Strategies for comprehending text and coping with reading difficulties. Learning Disability Quarterly, 12(1), 32-42. doi:10.2307/1510250

Pea, R. D. (2004). The social and technological dimensions of scaffolding and related theoretical concepts for learning, education, and human activity. Journal of the Learning Sciences, 13(3), 423-451. doi:10.1207/s15327809jls1303_6

Protopsaltis, A., \& Bouki, V. (2005, September). Toward a hypertext reading/comprehension model. In Proceedings of the 23rd Annual International Conference on Design of Communication: Documenting and Designing for Pervasive Information (pp. 159-166). New York, NY: Association for Computing Machinery. doi:10.1145/1085313.1085349

Puntambekar, S. (1995). Helping students learn 'how to learn' from text: Towards an ITS for developing metacognition. Instructional Science, 23, 163-182. doi:10.1007/BF00890450 
Ray, R. D. (2004). Adaptive computerized educational systems: A case study. In D. Moran \& R. Mallott (Eds.), Evidence-based educational methods (pp. 143-170). San Diego, CA: Elsevier Academic Press. doi:10.1016/B978-012506041-7/50011-5

Ray, R. D., Belden, N. (2007). Teaching college level content and reading comprehension skills simultaneously via an artificially intelligent adaptive computerized instructional system. The Psychological Record, 57, 201-218.

Ritchey, K. D., Silverman, R. D., Montanaro, E. A., \& Schatschneider, C. (2012). Effects of a tier 2 supplemental reading intervention for at-risk fourth-grade students. Exceptional Children, 78(3), 318-334. doi:10.1177/001440291207800304

Rouet, J. F., \& Levonen, J. J. (1996). Studying and learning with hypertext: Empirical studies and their implications. In J. J. Rouet, A. D. Levonen, \& R. J. Spiro (Eds.), Hypertext and cognition (pp. 9-23). Mahwah, NJ: Lawrence Erlbaum.

Salmerón, L., Kintsch, W., \& Cañas, J. (2006). Reading strategies and prior knowledge in learning from hypertext. Memory \& Cognition, 34(5), 1157-1171. doi:10.3758/BF03193262

Shang, H. F. (2005). E-mail dialogue journaling: Attitudes and impact on L2 reading performance. Educational Studies, 31(2), 197-212. doi:10.1080/03055690500095597

Shang, H. F. (2010). Reading strategy use, self-efficacy and EFL reading comprehension. Asian EFL Journal, 12(2), 18-42.

Shapiro, A., \& Niederhauser, D. (2004). Learning from hypertext: Research issues and findings. In D. H. Jonassen (Ed.), Handbook of research on educational communications and technology (pp. 605-620). Mahwah, NJ: Lawrence Erlbaum.

Sheorey, R., \& Mokhtari, K. (2001). Differences in the metacognitive awareness of reading strategies among native and non-native readers. System, 29, 431-449. doi:10.1016/S0346-251X(01)00039-2

Shuell, T. J. (1986). Cognitive conceptions of learning. Review of Educational Research, 56(4), 411-436. doi:10.3102/00346543056004411

Troffer, M. A. (2000). Writing effectively online: How to compose hypertext.

Unz, D. C., \& Hesse, F. W. (1999). The use of hypertext for learning. Journal of Educational Computing Research, 20, 279-295. doi:10.2190/FB08-5H94-3R3Y-KQLY

Vygotsky, L. S. (1978). Mind in society: The development of higher mental processes. Cambridge, MA: Harvard University Press

Wang, F., Kinzie, M. B., \& McGuire, P. (2010). Applying technology to inquiry-based learning in early children education. Early Childhood Education, 37, 381-389. doi:10.1007/s10643-009-0364-6

Wharton-McDonald, R., Pressley, M., \& Jampston, J. M. (1998). Literacy instruction in nine first-grade classrooms: Teacher characteristics and student achievement. The Elementary School Journal, 99(2), 101-128. doi:10.1086/461918

Wixson, K., \& Peters, C. (1984). Reading redefined: A Michigan reading association position paper. The Michigan Reading Journal, 17, 4-7.

Wood, D., Bruner, J. S., \& Ross, G. (1976). The role of tutoring in problem solving. Journal of Child Psychology and Psychiatry, 17(2), 89-100. doi:10.1111/j.1469-7610.1976.tb00381.x

Zhang, Z. (1993, November). Literature review on reading strategy research. Paper presented at the Annual Meeting of the Mid-South Educational Research Association, Lexington, Kentucky.

Corresponding author: Hui-Fang Shang, hshang@isu.edu.tw

Australasian Journal of Educational Technology (C) 2015.

Please cite as: Shang, H-F. (2015). An investigation of scaffolded reading on EFL hypertext comprehension. Australasian Journal of Educational Technology, 31(3), 293-312. 


\section{Appendix: Descriptive statistics for survey items}

\begin{tabular}{|c|c|c|}
\hline Perceived usefulness of teacher-guided instruction & Mean & SD \\
\hline Use appropriate reading strategies & 4.08 & .744 \\
\hline Understand main idea & 4.31 & .736 \\
\hline Use clue words to lead to the main idea & 3.73 & .875 \\
\hline Use own words to deliver the most important points & 3.38 & .853 \\
\hline Not useful to improve reading ability & $3.81 *$ & .939 \\
\hline Learn the knowledge of the text via teacher's explanations & 4.12 & 766 \\
\hline Instructor's explanations are helpful in enhancing reading comprehension & 3.69 & 788 \\
\hline Teacher's instruction improves reading performance & 3.88 & 766 \\
\hline \multicolumn{3}{|l|}{ Confidence of reading ability after teacher's instruction } \\
\hline Can use reading strategies effectively & 3.77 & .652 \\
\hline Can summarize the main idea in own words & 3.54 & 647 \\
\hline Can understand the content by the teacher's helpful explanations & 4.23 & .652 \\
\hline Waste time in the class & $4.31 *$ & .838 \\
\hline Can enhance reading skill to understand the main idea & 3.81 & .634 \\
\hline Can improve reading ability without attending the class & 3.12 & 1.070 \\
\hline Have more confident about reading performance & 3.62 & .752 \\
\hline Suffer from boredom in the class & $3.85 *$ & 1.00 \\
\hline Willing to read the magazine articles in the future & 3.96 & .774 \\
\hline \multicolumn{3}{|l|}{ Perceived usefulness of hypertext reading } \\
\hline Give greater control over reading process & 3.65 & .647 \\
\hline Save more time in reading & 3.91 & .900 \\
\hline Improve reading performance & 3.65 & .775 \\
\hline $\begin{array}{l}\text { Accomplish reading tasks more quickly, comparing with the traditional } \\
\text { reading tasks }\end{array}$ & 3.83 & .834 \\
\hline Reduce the time usually spent in reading & 3.96 & .899 \\
\hline Enhance effectiveness on reading tasks & 4.04 & .767 \\
\hline Easier to do the reading job & 3.96 & 1.260 \\
\hline Overall, the e-learning system is useful in reading. & 3.87 & .968 \\
\hline \multicolumn{3}{|l|}{ Perceived ease of hypertext use } \\
\hline Become confused when using the e-learning system & $4.04 *$ & .824 \\
\hline Make errors frequently when operating the e-learning system & $3.91 *$ & .793 \\
\hline $\begin{array}{l}\text { Need to consult with the teacher often about how to use the e-learning } \\
\text { system }\end{array}$ & $4.21 *$ & .902 \\
\hline Require a lot of mental effort when interacting with the e-learning system & $3.87 *$ & .869 \\
\hline Is rigid and inflexible to interact with the e-learning system & $3.57 *$ & .728 \\
\hline Is easy to get the e-learning system to do what I want it to do & 3.96 & .928 \\
\hline The e-learning system often behaves in unexpected ways. & $3.92 *$ & .848 \\
\hline Is difficult to use the e-learning system & $4.43 *$ & .728 \\
\hline Overall, I find the e-learning system easy to use. & 4.13 & .869 \\
\hline \multicolumn{3}{|l|}{ Attitude and attempt of future hypertext use } \\
\hline $\begin{array}{l}\text { Make wrong answers frequently when answering the reading } \\
\text { comprehension questions }\end{array}$ & $3.83 *$ & .834 \\
\hline Is often frustrating when interacting with the e-learning system & $3.91 *$ & .793 \\
\hline Provides helpful explanations in performing the reading tasks & 3.95 & 950 \\
\hline Suffer from boredom while doing the e-learning reading tasks & $4.22 *$ & .600 \\
\hline Can understand the main idea of the text via e-learning & 3.91 & .750 \\
\hline Can learn the knowledge of the text via e-learning & 3.87 & .694 \\
\hline More confident about my reading performance & 3.30 & .926 \\
\hline Willing to use the e-learning system in the future & 3.52 & 1.309 \\
\hline $\begin{array}{l}\text { Overall, I find the e-learning system helpful in enhancing my reading } \\
\text { comprehension performance. }\end{array}$ & 3.43 & 1.236 \\
\hline
\end{tabular}

* Items have been reversed. 